\title{
DANO MORAL: ANÁLISE DE ARGUMENTOS DECISÓRIOS EM ACÓRDÃO TRABALHISTA SOB A ÓTICA DA NOVA RETÓRICA
}

\author{
DAÑO MORAL: ANÁLISIS DE ARGUMENTOS DECISORIOS EN ACUERDO LABORAL SOB LA ÓPTICA DE \\ LA NUEVA RETÓRICA
}

MORAL DAMAGE: AN ANALYSIS OF THE ARGUMENTS RATED BY JUDGES FROM THE PERSPECTIVE OF NEW RHETORIC

\author{
Barbara Bedin* \\ Heloísa Pedroso de Moraes Feltes \\ Universidade de Caxias do Sul - UCS, BR
}

\begin{abstract}
RESUMO: Neste trabalho objetivou-se analisar os argumentos valorados por desembargadores para formar o entendimento do significado de dano moral - que equivale a um fenômeno jurídico passível de ser indenizado. Para alcançar tal objetivo, examinouse, em um estudo exploratório, o acórdão n. 0000192-11.2011.5.04.0001, proferido pela Quarta Turma do Tribunal Regional do Trabalho da Quarta Região (Rio Grande do Sul, Brasil), que trata de uma indenização por dano moral. Os argumentos foram levantados e analisados sob a ótica da Nova Retórica de Perelman e Olbrecht-Tyteca.

PALAVRAS-CHAVE: Nova Retórica; argumento; acórdão.
\end{abstract}

RESUMEN: Este estudio tuvo como objetivo analizar los argumentos valorados por los jueces para formar el entendimiento del significado de daño moral - que equivale a un fenómeno jurídico pasible de ser compensado. Para lograr este objetivo, se analizó, en un estudio exploratorio, el acuerdo n. O000192-11.2011.5.04.0001proferido por la Quarta Turma do Tribunal Regional do Trabalho da Quarta Região (Rio Grande do Sul, Brasil) que trata de la indenización por daños Morales. Los argumentos fueron recogidos y analizados sob la óptica de la Nueva Retórica de Perelman y Olbrecht-Tyteca.

PALABRAS-CLAVE: Nueva Retórica; argumento; acuerdo.

ABSTRACT: The aim of this study was to analyze the arguments rated by judges to form an understanding of the meaning of moral damage - which is equivalent to a legal phenomenon that can be compensated. To achieve this goal, in an exploratory study, was examined the Case no. O000192-11.2011.5.04.0001 delivered by the Fourth Chamber of the Regional Labor Court of the Fourth Region (Rio Grande do Sul, Brazil) which deals with moral damages. The arguments were sampled and analyzed from the perspective of New Rhetoric of Perelman and Olbrecht-Tyteca.

KEYWORDS: New Rhetoric; argument; judgment.

\section{INTRODUÇÃO}

Este estudo analisa, a partir de um caso concreto, ${ }^{1}$ as razões que embasam a ação de decidir em uma ação judicial, como forma de preencher as lacunas do sistema normativo. O arcabouço teórico-metodológico escolhido para a análise aqui empreendida é a Nova Retórica, através da obra de Perelman e OlbrechtTyteca, uma vez que temos como objetivo fazer um estudo metodológico do Direito no que tange aos juízos de valor no sistema jurídico.

Em termos da organização deste artigo, identificam-se, na primeira parte, os aspectos formais de uma sentença ou acórdão e sua condição de existência. Em seguida, apresenta-se uma breve conceituação sobre argumentação, partindo-se da Nova Retórica e sua aplicação na aderência de teses. Por fim, analisam-se os argumentos utilizados na fundamentação do acórdão para embasar a conclusão do que é dano moral. Não será discutida a questão do quantum indenizatório que também faz parte da fundamentação da decisão, mas tão somente os elementos levantados para conceituar o dano moral.

\footnotetext{
*Email: barbara@prelum.com.br.

1 Caso - Derivado do latim casus (acontecimento circunstância), na linguagem jurídica, é aplicado no mesmo sentido do evento, sucesso, isto é, tudo que acontece ou possa acontecer, sendo, às vezes, tomado no sentido próprio de circunstância, situação (SILVA, 2010, p. 270). Caso concreto, portanto, é um acontecimento, uma situação que gera efeitos jurídicos e, por esse motivo, é levada à apreciação do Poder Judiciário.
} 


\section{ASPECTOS FORMAIS E FUNCIONAIS DOS ACÓRDÃOS}

O acórdão é uma decisão prolatada por integrantes do Tribunal chamados desembargadores. As Turmas recebem processos distribuídos por sorteio das Varas do Trabalho de comarcas do estado. Esses processos tramitaram seguindo o rito estabelecido pelo Direito Processual do Trabalho com a apresentação de uma reclamação que desencadeou o cadastramento e processamento deste pedido, através de realização de audiência, apresentação de defesa, instrução do processo com realização de perícias técnicas, prova testemunhal e todos os meios idôneos permitidos para comprovar as alegações das partes e formar o entendimento do julgador. Encerrada a instrução processual, o Juiz de Primeiro Grau profere uma decisão chamada de sentença. A parte que não estiver satisfeita com o resultado poderá recorrer ao Tribunal Regional do Trabalho através de duas formas de recurso: recurso ordinário ou recurso adesivo. No Tribunal, quando o processo é distribuído para as Turmas, é nomeado um relator que fará sua exposição de motivos e proferirá seu voto no sentido de prover no todo ou em parte o recurso ou manter a decisão de primeiro grau. Os demais desembargadores poderão expor seus motivos e acompanharão ou não os argumentos e o voto apresentado pelo relator. Desse julgamento é formado o acórdão.

O acórdão deve ter a mesma estrutura da sentença e ser dividido em relatório, fundamentação e dispositivo ou conclusão, requisitos esses previstos no artigo 458 do Código de Processo Civil. Donizetti (2005, p. 5-10) explica essa estrutura: o relatório da sentença deve conter um breve histórico, o nome das partes, o resumo do pedido do autor e da resposta do réu e as principais ocorrências havidas no curso do processo. O dispositivo decorre do raciocínio desenvolvido na motivação e é o fechamento do documento onde o juiz acolhe ou rejeita o pedido do autor. A inexistência do relatório ou da motivação leva à nulidade da sentença, e a ausência do dispositivo conduz à inexistência do ato judicial. A fundamentação é uma parte muito importante da sentença porque, por meio dela, o magistrado aprecia a prova, observando os fatos e as circunstâncias presentes no processo e indica os motivos que formaram seu convencimento, mesmo que sejam argumentos não levantados pelas partes.

Fazem parte da sentença, mas não como requisitos essenciais, o preâmbulo e a ementa. O preâmbulo deve conter a natureza da ação, o número do processo e o nome das partes. A ementa representa um resumo das questões decididas no corpo da sentença ou acórdão e "proporciona ao leitor a antecipação da norma criada pelo julgador para regular o caso concreto, com os princípios e fundamentos expostos". A ementa é formada por duas partes: verbetação (sequência de palavras-chaves que indicam as questões analisadas na sentença) e dispositivo (norma estabelecida pelo juiz para regular o caso concreto), conforme descrição de Donizetti (2005, p. 2-3).

Slaib Filho (2004, p. 474) menciona que o preâmbulo não é considerado elemento essencial, mas é nele que se fazem constar dados que individualizam a decisão como a denominação do órgão, serventia, número de processo. No mesmo sentido, a ementa é facultativa, mas é cada vez mais utilizada, "quer pela importância crescente da jurisprudência e pelo dever do magistrado de tratar em igualdade de condições os casos similares, quer pelo emprego cada vez maior da informática, cujos bancos de dados exigem a classificação dos assuntos" (SLAIB FILHO, 2004, p. 477).

Donizetti (2005, p. 1-2) explica que a sentença apresenta três enfoques:

a) Enquanto ato processual é a síntese do processo que tem por objetivo a composição do litígio. $\mathrm{O}$ autor expõe a sua tese. $\mathrm{O}$ réu geralmente oferece resposta opositiva à pretensão objeto da tese - a antítese. A resposta do magistrado - a sentença - põe fim ao processo, acolhendo ou rejeitando o pedido do autor.

b) Enquanto objeto de análise da lógica aristotélica - "a sentença expressa um silogismo”: premissa maior - é o ordenamento jurídico que serve de contexto/base para a apreciação do direito invocado pelo autor como para a resistência apresentada pelo réu; premissa menor fundamentação fática exposta pelo autor no pedido inicial com o objetivo de demonstrar a procedência do pedido e daí decorrente ou retirado do conjunto probatório; e conclusão - ato pelo qual o juiz, fazendo a subsunção dos fatos às normas, extrai as consequências jurídicas e dá uma resposta ao postulado pelo autor.

c) Enquanto trabalho científico - a sentença é um texto complexo, predominantemente dissertativo, composto de relatório, fundamentação e dispositivo ou conclusão. O relatório é 
formado por uma exposição circunstanciada, um histórico, da marcha procedimental. A fundamentação expõe as razões do convencimento do magistrado, os motivos da decisão e o porquê da forma da decisão. A conclusão resolve as questões que as partes apresentaram, acolhendo ou rejeitando o pedido do autor ou extinguindo o processo sem julgamento do mérito.

Slaib Filho (2004, p. 497-510) salienta que a sentença deve atender a algumas condições importantes, entre outras: (a) clareza, já que, para que a atividade do Poder Judiciário seja legítima, a sentença deve ser fundamentada, e a decisão deve ser congruente com sua motivação, o que possibilita a interposição de recurso para ser apreciado no segundo grau pela parte que não ficou satisfeita; (b) linguagem simples com sentença inteligível ao padrão comum das pessoas, em determinada comunidade; (c) linguagem com expressão categórica, veemente, porque a sentença, sendo ato de poder, não pode ser manifestada de forma exultante, e seu conteúdo não pode ser condicionado; (d) precisão, no sentido de atender exatamente ao que foi pedido, nem mais nem menos, nos termos do que preceitua o artigo 460, do Código de Processo Civil.

\section{A NOVA RETÓRICA COMO BASE PARA A ANÁlISE DO ACÓRDÃo}

A decisão dos magistrados é tomada com base nos fatos, documentos e provas apresentados nos autos do processo e na adesão aos argumentos de uma das partes, representando a interpretação que foi dada pelos desembargadores ao caso concreto. Alexy (2010) explica que, a partir de argumentos apresentados, surgem "várias alternativas de interpretação" e que a isso corresponde que "nos sistemas jurídicos modernos existe um dever de fundamentação judicial e na ciência do direito são solucionados problemas pela consideração de argumentos-pró e contra." (p. 65-66).

Quando as opiniões entre os indivíduos são diferentes, elas têm uma distância, e a retórica negocia essa distância para se chegar a uma resposta que é dada através de um acordo. Esse acordo remete à ideia de adesão ou persuasão ${ }^{2}$ que foi singularizada pela argumentação de Aristóteles a Perelman, segundo Meyer (2007, p. 26), e é essa adesão aos argumentos que vamos analisar no acórdão objeto de estudo.

Ao se estudar a evolução histórica do pensamento jurídico, verifica-se que ela reflete-se de forma direta sobre o raciocínio jurídico, e a perspectiva argumentativa mais flexível surge como alternativa entre o positivismo lógico voltado ao direito e as discussões jurídicas totalmente irracionais. Monteiro (2006) explica que, por muitos séculos, "a produção judicial estava preocupada com a justiça de suas decisões, dando grande importância aos precedentes, devido à ideia de que os casos essencialmente similares deveriam ser tratados com igualdade" (p. 144).

Conforme Atienza (2006): a partir da Revolução Francesa, ocorre uma série de mudanças fundamentais no Direito:

O Direito é entendido como o conjunto de leis que são expressão da soberania nacional, aparecem sistemas jurídicos bem elaborados, o papel dos juízes se reduz ao mínimo e se estabelece a obrigação de apresentar o motivo das sentenças, que passam a ser também objeto de conhecimento público. (p. 76).

Perelman (2004b, p. 183-185) afirma, por exemplo, que o processo de Nuremberg ${ }^{3}$ evidenciou o fato de que a legislação de um Estado pode ser injusta e até mesmo criminosa. Desse modo, começaram a surgir orientações de teóricos do direito antipositivistas, que buscavam soluções não apenas em conformidade com a lei, mas também decisões equitativas, razoáveis, que fossem, ao mesmo tempo, justas e adequadas ao direito vigente.

\footnotetext{
2 A retórica teve grande importância na Grécia e Roma antiga, mas perdeu espaço quando os direitos políticos foram tolhidos pela queda do regime republicano no Império Romano. Foi resgatada na segunda metade do século XX, através do surgimento da comunicação de massa e reconquista da liberdade política. Está presente no cotidiano das pessoas, valorizando o interlocutor que tem a "capacidade para debater, para reagir e para interagir em face de problemas, propostas e teses apresentadas.” (ESTEVÃO, 2010, p. 141).

${ }^{3}$ Foram processos realizados no Tribunal Militar Internacional para julgar criminosos de guerra - entre eles, médicos, juristas, representantes do governo - após o término da Segunda Guerra Mundial. Tais processos enfrentaram dilemas para atribuir responsabilidade penal sobre atos condenáveis que não estavam definidos como crime na ordem internacional. Era necessário ultrapassar o princípio da legalidade, mas ainda assim justificar as decisões pelo Direito.
} 
Cyrillo da Silva (2007, p. 12-13) esclarece que o sistema normativo de um Estado por si só é insuficiente para dar conta de todas as situações existentes no Direito, devendo se ocupar, também, dos conflitos da prática jurídica, atentando-se para as razões de decidir do juiz, ou seja, para a argumentação no processo.

Perelman e Olbrechts-Tyteca (2005) explicam qual é o objetivo de toda argumentação

[...] provocar ou aumentar a adesão dos espíritos às teses que se apresentam a seu assentimento: uma argumentação eficaz é a que consegue aumentar essa intensidade de adesão, de forma que se desencadeie nos ouvintes a ação pretendida (ação positiva ou abstenção) ou, pelo menos, crie neles uma disposição para a ação, que se manifestará no momento oportuno. (p. 50)

O que analisamos no acórdão é justamente a quais teses os desembargadores aderiram e quais os argumentos que foram considerados mais fortes para eles. Perelman (2004b, p. 156) explica que a argumentação não visa à adesão exclusivamente pelo fato de a tese ser verdadeira. Por parecer mais equitativa, mais oportuna, mais útil, mais razoável, mais adequada à situação é que uma tese pode ser preferida à outra.

Para evitar um erro de argumentação, Perelman defende que "o orador deve conhecer seu auditório ou, ao menos, os posicionamentos deste em relação ao assunto abordado" (2004b, p. 157), o que justifica o estudo do acórdão, dada a necessidade de os advogados conhecerem os entendimentos daqueles que julgam os processos por eles patrocinados.

A eficácia da argumentação depende da adesão do auditório, ou seja, no caso de nosso objeto de análise, depende da aceitação dos argumentos pelos desembargadores que julgam o processo e, portanto, nas palavras de Perelman, a argumentação "deve apoiar-se em teses admitidas pelo auditório" (2004a, p. 325). Ou seja, os advogados devem apresentar argumentos de tal natureza que possam ser convincentes e aceitos pelos magistrados para embasar suas teses.

Para conhecer as teses admitidas pelo auditório, precisamos identificar o que é percebido como relevante para os julgadores e analisar, de forma cuidadosa, a estruturação argumentativa, o que o faremos à luz da perspectiva construída por Perelman.

Esse enfoque dado através da Nova Retórica permite a união da atividade jurídica (prática) com a produção doutrinária, permitindo que se aprimorem técnicas de argumentação destinadas a promover um resultado positivo nos processos judiciais, por exemplo.

Perelman e Olbrechts-Tyteca estruturam as técnicas argumentativas através de uma divisão entre os argumentos quase-lógicos e os argumentos baseados na estrutura do real. Nesse estudo é feita uma seleção dos principais argumentos que foram utilizados na análise do acórdão.

\subsection{Os argumentos quase lógicos}

Os argumentos quase-lógicos, segundo Perelman e Olbrechts-Tyteca (2005), se comparam aos raciocínios formais lógico-matemáticos de natureza não-formal, que se aproximam das estruturas de raciocínio rigoroso, formal e demonstrativo, o que lhes confere uma força persuasiva toda especial.

\section{Incompatibilidade}

Em um sistema aberto como a linguagem natural, os enunciados, segundo Perelman e Olbrechts-Tyteca (2005), são interpretáveis e sujeitos a ambiguidades, polissemias, vaguidades, e o que existe é a incompatibilidade de argumentos. Em determinadas situações, conforme apontam esses autores, essa incompatibilidade poderá ser indicada e também desfeita, uma vez que as interpretações dependem da natureza das coisas a que se referem, das circunstâncias enunciativas e do próprio esforço interpretativo do interlocutor.

A incompatibilidade, além disso, difere da contradição, uma vez que em um sistema lógico-formal os enunciados são unívocos e a asserção de uma proposição e de sua negação simultaneamente torna o sistema incoerente ou contraditório. 
Nesse sentido manifestam-se os autores:

A contradição lógica, discernível de um modo puramente formal é intimamente ligada ao sistema e independente de nossa vontade e das contigências, pois é inelutável no âmbito das convenções aceitas. Não é isso que se dá com a argumentação, onde as premissas apenas raramente são inteiramente explicitadas e, quando o são, raramente definidas de um modo inteiramente unívoco; nela, o campo e as condições de aplicação variam com as circunstâncias, das quais, aliás, fazem parte as próprias decisões dos participantes do debate. (PERELMAN; OLBRECHTS-TYTECA, 2005, p. 222).

Em sua obra, os autores apresentam os procedimentos para evitar a incompatibilidade, bem como técnicas que visam apresentar as teses como compatíveis ou incompatíveis.

A regra de justiça

A regra de justiça afirma que seres ou situações de uma mesma categoria (ou que integram uma mesma categoria) devem ter um tratamento idêntico, supondo uma etapa de classificação e categorização. Baseia-se na expectativa de coerência de uma conduta.

Argumentação pelo sacrifício

É um tipo de argumentação de comparação e diz respeito a um sacrifício que se está disposto a suportar para obter determinado resultado. Aplica-se a todo o domínio das relações de meio-fim, o meio sendo o sacrifício, um esforço, um sofrimento. Avaliar ou valorizar alguma coisa mediante os meios utilizados para produzi-la, o sacrifício necessário para alcançá-la consiste no aspecto quase-lógico.

\section{Probabilidades}

As probabilidades também são espécies de argumentos comparativos que visam aos problemas ou às questões em um sentido empírico, consistindo em fazer avaliações tanto sobre a importância dos acontecimentos quanto sobre a probabilidade de sua aparição.

\subsection{Os argumentos baseados na estrutura do real}

Os argumentos baseados na estrutura do real buscam estabelecer solidariedade entre juízos admitidos e outros que se procura promover. A solidariedade "serve para vencer uma resistência, para provocar a adesão ao que não se quer, para obter o que se quer" (PERELMAN; OLBRECHTS-TYTECA, 2005, p. 298). Consideramos, aqui em nossa exposição, os principais argumentos baseados na estrutura do real.

O argumento pragmático

Esse argumento consiste em apreciar um ato ou um acontecimento de acordo com suas consequências favoráveis ou desfavoráveis, ou seja, os seus efeitos. É um argumento que se desenvolve sem grandes dificuldades, uma vez que não precisa de qualquer justificação para ser aceito pelo senso comum.

\section{$O$ argumento de autoridade}

Esse tipo de argumento tem seu alcance condicionado ao prestígio. Utilizam-se atos ou juízos de uma pessoa ou de um grupo de pessoas como meio de prova em favor de uma tese. Quando se quer questionar um argumento de autoridade se questiona a autoridade invocada e não seu argumento.

\section{Argumentos de bierarquia}

As hierarquias, como os valores, fazem parte dos acordos que servem de premissas para os discursos. Contudo, pode-se questionar e argumentar a respeito delas, considerando-se de que forma são fundamentadas, onde seus termos devem se situar.

Muitas vezes, segundo Perelman e Olbrechts-Tyteca (2005), se discutem os argumentos de hierarquia dupla - que é a correlação entre a hierarquia discutida e a hierarquia aceita - e, normalmente, exprime-se uma ideia de proporcionalidade, direta ou inversa, ou, pelo menos, um vínculo entre termo a termo. 
Os argumentos de hierarquia podem ser quantitativos ou qualitativos. Os argumentos de hierarquia quantitativos são mais fáceis de identificar já que tratam de dados estatísticos, diferenças numéricas, de grau ou de intensidade. Os argumentos de hierarquia qualitativos não podem ser descritos nem fundamentados por meio de elementos mensuráveis e é onde a argumentação adquire maior importância, já que se utiliza de outras hierarquias, normalmente extraídas do mundo físico, para sustentar essas hierarquias.

\section{ANÁLISE DOS ARGUMENTOS DO ACÓRDÃo}

Na decisão estudada, foi mantida a sentença de primeiro grau que condenou uma empresa ao pagamento de indenização por danos morais, tendo sido, portanto, configurado o assédio moral durante o contrato de trabalho. A ementa do acórdão ficou assim disposta:

INDENIZAÇÃO POR DANO MORAL. A exposição do reclamante à situações humilhantes evidencia abuso de direito do empregador, tornando evidentes o constrangimento e o abalo moral sofridos pelo trabalhador na vigência do contrato de trabalho, situação definida na doutrina e jurisprudência como assédio moral. Configurado o dano moral de que tratam os incisos $\mathrm{V}$ e $\mathrm{X}$ do art. $5^{\circ}$ da Constituição Federal, o reclamado deve ser condenado ao pagamento da indenização correspondente, fixada de forma tal a atender à finalidade da compensação do dano e à função pedagógico-punitiva. Sentença mantida.

Uma parte da ementa que é retomada na fundamentação diz que: "configurado o dano moral de que tratam os incisos $\mathrm{V}$ e X do art. $5^{\circ}$ da Constituição Federal, o reclamado deve ser condenado ao pagamento da indenização correspondente [...]”.

Os incisos $\mathrm{V}$ e $\mathrm{X}$ da $\mathrm{CF} / 88$ assim estabelecem:

V - é assegurado o direito de resposta, proporcional ao agravo, além da indenização por dano material, moral ou à imagem;

$\mathrm{X}$ - são invioláveis a intimidade, a vida privada, a honra e a imagem das pessoas, assegurado o direito a indenização pelo dano material ou moral decorrente de sua violação.

Os referidos artigos não esclarecem o que é o dano moral; apenas indicam que quando ele for configurado é possível a sua reparação. A letra da lei abre espaço para a interpretação e construção do conceito de dano moral através da análise dos argumentos partindo da Nova Retórica de Perelman (2004a, 2004b).

Após a estruturação legal do acórdão, o relator apresenta seu voto, que é acompanhado pelos demais desembargadores para manter a decisão de primeiro grau que julgou procedente o pedido do autor e condenou a empresa ao pagamento de uma indenização por danos morais.

O relator descreve os argumentos apresentados pelo reclamante e pelo reclamado e assim se manifesta, conforme (1):

(1) Feitas tais considerações, a CF, em seu art. $5^{\circ}, \mathrm{X}$, dispõe que "São invioláveis a intimidade, a vida privada, a honra e a imagem das pessoas, assegurando o direito à indenização pelo dano material ou moral decorrente de sua violação." Vale dizer, como ali assegurado, que toda pessoa goza de prerrogativas inerentes à sua qualidade de pessoa humana, os ditos direitos de personalidade, em cujo núcleo reside o valor da dignidade. ${ }^{4}$

Ele assevera que o núcleo dos direitos de personalidade abriga a dignidade da pessoa humana, e é essa violação que gera o dano moral. Para dar força a essa premissa da argumentação, o relator do acórdão utiliza uma doutrina como argumento, expresso em (2):

(2) O dano moral nada mais é do que a violação destes direitos de personalidade, que na conceituação de Maria Helena Diniz (Responsabilidade Civil, SP, Saraiva, 1988, p. 73), citada por Glaci de Oliveira Pinto Vargas (Reparação do Dano Moral - Controvérsias e Perspectivas, Porto Alegre, Ed. Síntese, p. 17),

"Consiste na lesão a um interesse que visa à satisfação ou ao gozo de um bem jurídico extrapatrimonial contido nos direitos da personalidade (a vida, a integridade corporal, a liberdade, a honra, o decoro, a

\footnotetext{
${ }^{4}$ Os excertos analisados têm sua escrita mantida conforme o original.
} 
intimidade, os sentimentos afetivos, a própria imagem) ou nos atributos da pessoa (o nome, a capacidade, o estado de família)". (Grifos nosso).

Essa doutrina é considerada um argumento de autoridade, ou seja, uma fonte que possui condições para responder aquilo que se busca. Para ser um bom argumento de autoridade, Weston (2009, 32-36) explica que ele deve atender a determinados requisitos: citação das fontes (partes grifadas), qualificação das fontes, imparcialidade das fontes.

O relator do acórdão socorre-se, ainda, em (3), da legislação, através do Código Civil brasileiro, não explicando o que é o dano moral, mas argumentando que decorre de violação ou abuso de direito gerando a obrigação de indenizar:

(3) De outro lado, nos termos do CC, o dano, inclusive o moral, decorre de prática de ato ilícito do ofensor por violação de direito, nos termos definidos no art. 186, ou por abuso de direito, consoante o art. 187, nascendo daí a obrigação de indenização na forma do art. 927, observada a sua dupla finalidade, qual seja de compensação à vítima e pedagógico-punitiva.

Mais adiante, em (4), o relator refere que o empregado/reclamante sofreu assédio moral que se enquadra em uma das espécies de dano moral e, aí sim, em (4.1), conceitua esse assédio como sendo a prática reiterada de conduta abusiva pelo empregador, empregados ou prepostos e que acarretam danos físicos e psíquicos ao indivíduo:

(4) Por sua vez, o assédio moral - a que se refere o reclamante e que se enquadra em uma das espécies de dano moral -, consiste na prática reiterada de conduta abusiva, pelo empregador, diretamente ou por meio de seus prepostos ou empregados, que traduz uma atitude ostensiva de perseguição ao empregado, repetindo-se no tempo, de tal modo que possa acarretar danos importantes às condições físicas e psíquicas, afetando a sua auto-estima. (4.1) Para restar caracterizado o assédio moral, portanto, imprescindível que a conduta ilícita dirigida ao empregado de forma ostensiva seja praticada diversas vezes, prolongando-se no tempo. Além disso, o assédio moral no ambiente de trabalho deve ser analisado pelo prisma do conteúdo subordinado da relação jurídica de emprego, porquanto o empregado encontrase naturalmente tolhido em face de eventual conduta abusiva do empregador.

Para caracterizar o dano moral, em (5), argumenta o relator que não existe necessidade de provar esse dano. Basta comprovar que o fato gerador como causador do dano aconteceu e, se ele viola os direitos de personalidade do reclamante, será considerado um dano moral:

(5) Ademais disso, impõe-se referir que embora não se exija prova do dano moral propriamente dito, imprescindível é a prova do fato gerador alegado como o causador do dano e, além disso, há que se examinar se este fato efetivamente é causador de dano moral, ou seja, se há violação de direitos de personalidade da reclamante.

O reclamante valeu-se de prova testemunhal para tentar comprovar o alegado, conforme (6), sendo que a única testemunha apresentada foi contraditada pela empresa reclamada por ter proposto também uma reclamatória trabalhista contra o mesmo empregador. A contradita não foi aceita pelo relator, uma vez que a propositura de uma demanda, por si só, não é motivo para diminuir o valor do depoimento prestado:

(6) No caso foi ouvida uma única testemunha, cuja contradita, ao argumento de mover ação contra o reclamado, foi indeferida pelo Juízo da origem na forma da SJ 357 do TST (fl. 285). A respeito, em atenção às razões recursais que questionam a validade deste depoimento como meio de prova, esclareço que adoto, também, a orientação que emana do referido entendimento jurisprudencial. Isto porque o exercício do direito constitucional de ação, buscando tutela de direitos supostamente lesados junto ao Poder Judiciário, não configura, ainda que verificada identidade com prestações vindicadas no presente feito, quaisquer das hipóteses de suspeição previstas nos artigos 829 da CLT e 405, § $3^{\circ}$, do CPC.

Observa-se, nesse caso, que a reclamada fez uma tentativa de argumentação contra a pessoa da testemunha, ou seja, ad personam, ${ }^{5}$ utilizada, em regra geral, quando se tem poucas chances de vencer um debate, ou

\footnotetext{
${ }^{5}$ Utiliza-se o conceito ad personam da mesma forma que Chaïm Perelman em suas obras. Esse autor faz uma diferença entre o argumento ad personam e o argumento ad hominem, sendo que o primeiro é um ataque visando desqualificar o indivíduo enquanto que o segundo, aquele que teve uma tese refutada, com qualquer que seja a técnica, tem seu prestígio diminuído. Ambos os argumentos estão interligados e, por esse motivo, são confundidos (PERELMAN; OLBRECHTS-TYTECA, 2005, p. 126). Michel Meyer, por sua vez, não faz essa distinção e conceitua o argumento ad hominem como sendo um ataque visando desqualificar o indivíduo (MEYER, 2007, p. 50).
} 
persuadir, se valendo somente do argumento ad rem, voltando-se para um ataque direto à pessoa que defende o ponto de vista contrário, visando, essencialmente, sua desqualificação, conforme explica Perelman (2005, p. 126). No caso da testemunha, o ataque pessoal se dá com a intenção de configurar que ela não é imparcial e diminuir o valor de seu depoimento, já que também demanda contra a reclamada. ${ }^{6}$

Weston (2009, p. 39) entende que determinadas testemunhas podem ser desqualificadas nos casos em que não forem abalizadas, imparciais ou se não existir um mínimo de consenso entre elas, sendo que outros tipos de ataques pessoais não seriam legítimos. O relator do processo não acolheu o argumento de não imparcialidade levantado pela empresa recorrente.

O empregado, em (7), argumenta que sofreu um rebaixamento funcional ou não lhe foram concedidas as promoções devidas relacionadas ao seu cargo, e que tal situação é causadora de dano moral, uma vez que teve perdas materiais relacionadas com essa situação. $O$ relator do processo não recepcionou esse argumento, com a justificativa de que a alegada perda material não acarreta dano moral ao empregado, mas, como ele mesmo afirmou, uma perda material que deve ser buscada através de ação própria:

(7) [...] as questões relativas ao suposto rebaixamento funcional e/ou a não concessão das promoções devidas são pertinentes à ação de reparação por danos materiais, na qual inclusive já providenciou o ora recorrido, segundo noticiado na sentença. (Grifo nosso).

O fato de existir um inadimplemento econômico e, inclusive, a procedência da ação de reparação de danos materiais, por si só, não configura o dano moral ao empregado, que deverá comprovar efetivamente que esse inadimplemento tenha gerado o dano moral, conforme (8):

(8) De ver que o eventual reconhecimento do direito pretendido, com as devidas consequências previstas em lei, por si só não gera dano moral, necessitando para tanto prova de que o inadimplemento tenha gerado efetiva dor moral, o que não há razão pela qual os fatos noticiados, no particular, não se prestam para amparar o pedido de indenização correspondente.

Em (5), o relator declara ser suficiente, para caracterizar o dano moral, não a prova do dano, mas a comprovação de que o fato gerador do dano aconteceu. Em (8), o relator questiona a correlação entre "inadimplemento" e "dano moral" - o que precisa ser provado não é o dano, mas que o inadimplemento seja fato gerador de dano.

É importante acompanhar a forma como os argumentos são utilizados pelas partes e desembargadores para evitar incompatibilidades e sua possível refutação. A incompatibilidade de argumentos ocorreu porque, com fundamento na Nova Retórica, os enunciados se apresentam em um sistema aberto, com linguagem natural e são interpretáveis sujeitos a ambiguidades, polissemias e vaguidades. ${ }^{7}$

Feltes (2003) explica a semelhança da incompatibilidade com a contradição do sistema lógico-formal:

Estas são algo semelhante às contradições, mas, ao contrário destas, são estabelecidas entre enunciados cuja interpretação depende da natureza das coisas a que se referem, das circunstâncias enunciativas e do próprio esforço interpretativo do interlocutor. E, em assim sendo, haverá situações em que tanto será possível indicar como também desfazer incompatibilidades. (p. 264).

A incompatibilidade de argumentos pode fundamentar eventual recurso de uma das partes para tentar reverter as decisões que foram desfavoráveis a cada uma delas.

Um argumento acolhido pelos desembargadores para condenar o empregador ao pagamento de indenização por danos morais foi o de que "ócio remunerado" caracteriza dano moral passível de indenização. O empregado cumpriu um mandato de Diretor-Presidente e, ao retornar à sua função original, não foi designada qualquer tarefa para ele realizar. Essa situação, no entendimento dos magistrados, lhe causou

\footnotetext{
${ }^{6}$ Antes de iniciar seu depoimento, a testemunha presta compromisso de dizer a verdade sobre os fatos que lhe são perguntados (art. 415, CPC). Se o depoente for declarado suspeito, por exemplo, por ter interesse na causa, poderá ser ouvido como informante, e o juiz atribuirá aos depoimentos “o valor que possam merecer" (art. 405, $\left.\$ 4^{\circ}, \mathrm{CPC}\right)$.

${ }^{7}$ Embargos de declaração estão previstos no nosso ordenamento jurídico para provocar o magistrado a esclarecer suas decisões quando estas forem consideradas contraditórias, obscuras ou omissas por uma das partes.
} 
extremo constrangimento, conforme se comprova com a fundamentação apresentada no corpo do acórdão em (9), (9.1) e (9.2), respectivamente:

(9) [...] ócio remunerado, como classificado na sentença, agiu com abuso de direito capaz de ensejar danos de natureza extrapatrimonial e como tal suscetíveis de reparação na forma do art. 927 do CC.

(9.1) [...] após expirado o mandato de Diretor- Presidente da CABERGS, relegado ao ostracismo e pois submetido à situação de extremo constrangimento, para dizer o mínimo

(9.2) [...] não lhe eram delegadas quaisquer tarefas, ou seja, comparecia diariamente ao banco apenas para cumprir sua jornada de trabalho (nas palavras da testemunha, "não fazia nada").

A argumentação ad personam utilizada, em regra geral, para desconstituir ou tirar a credibilidade de uma autoridade foi aplicada, conforme (10), ao contrário, para elevar o valor do reclamante, para demonstrar que sua imagem foi maculada:

(10) [...] e cuja repercussão toma ainda maiores proporções quanto se considera o histórico funcional do reclamante, que chegou a ocupar cargos da mais alta hierarquia tanto na organização do banco reclamado (Gerente Geral) quanto na CABERGS (Diretor-Presidente da entidade assistencial mantida pelo BANRISUL. (Grifo nosso).

Observa-se que em (11), em sua argumentação, o relator retoma o conceito de assédio moral utilizado no início da fundamentação (4), explicando que é uma espécie de dano moral caracterizado por ações do empregador prejudiciais ao empregado, e que são reiteradas e aqui acrescentada a informação de que ocorreram ao longo de aproximadamente cinco anos:

(11) [...] repercussões negativas na auto-estima do empregado derivadas do sentimento de humilhação com o tratamento a si dispensado, agravado dia-a-dia ao longo de aproximadamente cinco anos.

A Lei de Introdução às Normas do Direito Brasileiro (Decreto-Lei n. 4.657, de 04/09/1942) estabelece a utilização de fontes do Direito em caso de decisão judicial quando a lei for omissa:

Art. $4^{\circ}$ Quando a lei for omissa, o juiz decidirá o caso de acordo com a analogia, os costumes e os princípios gerais de direito.

Art. $5^{\circ} \mathrm{Na}$ aplicação da lei, o juiz atenderá aos fins sociais a que ela se dirige e às exigências do bem comum.

Para manter a condenação da empresa ao pagamento de indenização por danos morais, o relator recorreu ao senso comum argumentando, em (12), que também por ele é possível identificar a violação à dignidade da pessoa:

(12) [...] exclusão das atividades produtivas, foram de tal monta que é razoável compreender, pelo senso comum, tenha-se sentido indignado e atingido na sua auto-estima profissional, pelo evidente menosprezo de sua condição de pessoa digna de trabalhar, condição esta de resto demonstrada por sua trajetória profissional.

Na análise realizada, observa-se que a decisão dos Desembargadores não está fundada exclusivamente na lei positiva, mas através da escolha de argumentos de natureza diversa apresentados pelas partes ou pelos próprios julgadores como argumentos de autoridade (a doutrina), ad hominem (tentando desqualificar a testemunha e qualificando o autor do processo) e fontes do Direito (arguindo o senso comum).

Perelman (2005) afirma que o Direito, tal como funciona, é um problema de decisão, pois

o legislador deve decidir quais serão as leis obrigatórias numa comunidade organizada, o juiz deve decidir sobre o que é o direito em cada situação submetida ao seu juízo. Mas nem o legislador nem o juiz tomam decisões puramente arbitrárias: a exposição dos motivos indica razões porque uma lei foi votada e, num sistema moderno, toda sentença deve ser motivada. (p. 376).

A decisão judicial traduzida através do acórdão é imperativa, ou seja, obrigatória, mas, ao mesmo tempo, ela é retórica, argumentativa. E a motivação judicial para não ser irracional deve traduzir a lógica dos argumentos de uma forma procedimental através da justificativa de aplicação de determinados 
fundamentos. Essa é a proposta de Perelman, ao adotar um novo paradigma de racionalidade jurídica que corresponda à prática judiciária contemporânea, a qual que tentamos aplicar na análise desse acórdão.

\section{CONSIDERAÇÕES FINAIS}

O estudo realizado foi apenas exploratório, mas contribuiu para iniciarmos uma análise das decisões judiciais através da Nova Retórica de Perleman e Olbretch-Tyteca, buscando construir o conceito de dano moral a partir dos casos concretos e onde a teoria dos autores está centrada, ou seja, preocupação no decidir. Cyrillo da Silva (2007) explica que isso deve-se ao foco "nas razões colocadas pelo juiz, quando, diante de um caso concreto, aplica a lei, interpreta, com o intuito de tomar a decisão coerente e aceitável, bem como, conforme o fim do Direito" (p. 38).

A preocupação com o decidir se dá porque toda a lei é universal e, em tese, abrange todos os fatos sociais. Contudo, em determinadas ocasiões ou em determinados casos particulares não é possível regular universalmente esse caso. Assim, cabe ao julgador, de uma forma equânime - através do processo interpretativo - corrigir a lacuna da lei.

O processo interpretativo torna a análise complexa e, segundo Gadamer (2008, p. 408), uma lei não quer ser entendida historicamente, e a interpretação deve concretizá-la em sua validade jurídica. Para uma compreensão do verdadeiro significado do texto e compreendê-lo com as pretensões que apresenta, é necessário compreendê-lo a cada instante, em cada caso concreto de uma forma e distinta e, nesse caso, compreender é sempre aplicar.

No acórdão estudado, verificamos que os argumentos apresentados pelos magistrados para caracterizar o dano moral são construídos no caso concreto. Utilizam-se as fontes do Direito, mas analisando, efetivamente, a situação em particular. Feltes (2003) afirma que "toda compreensão está aberta às situações sempre mutáveis em que os textos são entendidos” (p. 281) e, nas decisões judiciais, seu sentido é construído no caso concreto através da compreensão, interpretação e aplicação.

\section{REFERÊNCIAS}

ALEXY, Robert. Direito, razão, discurso: estudos para a filosofia do direito. Trad. Luís Afonso Heck. Porto Alegre: Livraria do Advogado, 2010.

ATIENZA, Manuel. As razões do direito: teorias da argumentação jurídica. Trad. Maria Cristina Guimarães Cupertino. São Paulo: Landy Editora, 2006.

CYRILLO DA SILVA, Carolina Machado. Chaim Perelman: da argumentação à justiça - um retorno a Aristóteles. Porto Alegre: Linus Editores, 2007.

DONIZETTI, Elpídio. Redigindo a sentença. 3. ed. Belo Horizonte: Del Rey, 2005.

ESTEVÃO, Roberto da Freiria. A retórica no direito: a lógica da argumentação jurídica e o uso da retórica na interpretação. São Paulo: Letras Jurídicas, 2010.

FELTES, Heloísa Pedroso de Moraes. A argumentação quase-lógica de Perelman \& Olbrecht-Tyteca: uma aplicação ao discurso científico-(contra-)argumentativo. In: SPAREMBERGER, Raquel Fabiana Lopes (Org.). Hermenêutica e argumentação: em busca da realização do Direito. Ijuí: Ed. da Unijuí; Caxias do Sul: Educs, 2003. (Coleção direito e política e cidadania, 12). p. 259-281.

GADAMER, Hans-Georg. Verdade e método I: traços fundamentais de uma hermenêutica filosófica. 10 ed. Petrópolis, RJ: Vozes, 2008.

MEYER, Michel. A retórica. São Paulo: Ática, 2007.

MONTEIRO, Cláudia Servilha. Teoria da argumentação jurídica e nova retórica. 3. ed. Rio de Janeiro: Lumen Juris, 2006.

PERELMAN Chaïm. Retóricas. 2. ed. São Paulo: Martins Fontes, 2004a. (Justiça e direito). Lógica jurídica: nova retórica. 2. ed. São Paulo: Martins Fontes, 2004b. (Justiça e direito). 
Ética e direito. 2. ed. São Paulo: Martins Fontes, 2005. (Justiça e direito).

; OLBRECHTS-TYTECA, Lucie. Tratado da argumentação: a nova retórica. Tradução por Maria

Ermantina Galvão Pereira. 2. ed. São Paulo: Martins Fontes, 2005. (trad. de Traité de l'Árgumentation. La Nouvelle Rhétorique, Paris: PUF, 1958)

SILVA, De Plácido e. Vocabulário jurídico. 28. ed. Rio de Janeiro: Forense, 2010.

SLAIBI FILHO, Nagib. Sentença cível: fundamentos e técnicas. Rio de janeiro: Forense, 2004.

WESTON, Anthony. A construção do argumento. São Paulo: Martins Fontes, 2009.

Recebido em 29/01/2013. Aprovado em 14/03/13. 